\title{
Dismembered and non-dismembered retroperitoneoscopic pyeloplasty for the treatment of ureteropelvic junction obstruction in children
}

\author{
Svetozar Subotic $\cdot$ Hagen Weiss $\cdot$ Stephen Wyler $\cdot$ \\ Cyrill A. Rentsch · Jens Rassweiler • \\ Alexander Bachmann • Dogu Teber
}

Received: 2 March 2012/ Accepted: 8 May 2012/Published online: 22 May 2012

(C) Springer-Verlag 2012

\begin{abstract}
Purpose Open dismembered pyeloplasty according to Anderson-Hynes (AHP) is the gold standard treatment for ureteropelvic junction obstruction in children. However, during the last decade, the management has been revolutionized with introduction of laparoscopy and endourology yielding comparable results and less morbid outcomes.

Methods Between 1997 and 2010, dismembered and nondismembered retroperitoneoscopic pyeloplasty was performed in 41 children with a median age of 130 month (range 5-192). 20 children underwent a dismembered pyeloplasty (Anderson-Hynes) and 21 children were operated by a non-dismembered pyeloplasty (Y-V-Plasty).

Results The mean operation time was 120 min (range 52-257). Intraoperative findings revealed in 29 cases a significant crossing vessel. Based on a furosemide nephrogram and subjective complaints, the success rate was $88 \%$ with a median follow-up of 69 month (range 14-142). The 5 failures (2 Y-V-Plasty, 3 AHP) have been treated by open AHP $(n=2)$, Laser endopyelotomy $(n=2)$ and Lap-AHP $(n=1)$ without further problems.

Conclusion With increasing improvement of the suture techniques, the laparoscopic pyeloplasty represents in
\end{abstract}

S. Subotic $(\bowtie) \cdot$ S. Wyler · C. A. Rentsch · A. Bachmann Department of Urology, University Hospital Basel, Spitalstr. 21, 4031 Basel, Switzerland

e-mail: subotics@uhbs.ch

H. Weiss · J. Rassweiler

Department of Urology, SLK Kliniken Heilbronn,

University of Heidelberg, Heidelberg, Germany

D. Teber

Department of Urology, University Hospital Heidelberg,

Heidelberg, Germany experienced hands an alternative method with comparable success rates to the open technique. In our opinion, retroperitoneoscopic pyeloplasty is technically possible and feasible even in infants. We found in our series no statistically significant difference between dismembered and non-dismembered pyeloplasty.

Keywords Ureteropelvic junction obstruction . Children · Anderson-Hynes - Retroperitoneoscopic pyeloplasty $\cdot$ Minimal invasive

\section{Introduction}

Ureteropelvic junction obstruction (UPJO) is the most common disorder of the upper urinary tract in children. As a result of progress in diagnostic ultrasound, hydronephrosis can nowadays even be identified prenatally [1]. Ultrasonography still remains the primary diagnostic tool for the detection of UPJO in children. The classification of hydronephrosis is based on the recommendation of the Society for Fetal Urology (SFU). In all children with UPJO, a preoperative furosemide nephrogram was additionally performed to evaluate the functional relevance of the stenosis. MRI has been described as an alternative method with the advantage of visualizing crossing vessels. Following critical analyses of various diagnostic methods, some authors have demonstrated superiority with duplex ultrasonography due to the ability of identifying the resistance index (RI) [2]. RI has been proven to be a useful and minimal invasive method particularly in the follow-up of significant UPJO patients.

Untreated UPJO can lead to a significant reduction of kidney function and may result eventually in renal failure. Traditionally, open pyeloplasty has been the gold standard 
treatment for UPJO in children with success rates being quoted at over $90 \%$ [3]. Specifically, due to confined working conditions and difficulties with anastomotic suturing, open access was required.

With the introduction of laparoscopy during the last decade, the management of UPJO has been revolutionized. Endourology yields not only comparable results, but also less morbid outcome. With growing experience in laparoscopic techniques, there has gradually been a transition in paediatric surgery from ablative techniques to reconstructive procedures. Besides the established procedures like the laparoscopic nephrectomy and orchidopexy, procedures such as heminephrectomy and pyeloplasty have also proven to be applicable and feasible in both children and infants, respectively [4-16]. Penn et al. found near equal results regarding outcomes in a comparative study laparoscopic pyeloplasty versus open approach [3].

The first laparoscopic pyeloplasty for children was described by Schuessler, 1993 [17] and Kavoussi [14]. Since then, suturing techniques together with improved visualization of the structures have developed rapidly. As a result, a number of larger centres have introduced the laparoscopic technique because of its minimal invasiveness. Recently, Kutikov et al. [18] reported on a series of 8 infants aged between 3 and 5 months with UPJO who were treated with a laparoscopic transperitoneal dismembered pyeloplasty. A $100 \%$ resolution of the UPJO was reported in this series postoperatively, a single infant had unchanged hydronephrosis though without significant obstruction. The authors concluded that even in children less than 6 months, a laparoscopic pyeloplasty is technically feasible.

Various authors presented their experiences using different techniques (i.e. dismembered and non-dismembered pyeloplasty) with success rates of more than $90 \%$. Casale et al. [7] reported on 26 children who underwent both a dismembered and non-dismembered laparoscopic pyeloplasty. The non-dismembered pyeloplasty was performed by Heineke-Mikulicz technique with a poor success rate of $43 \%$. Therefore, a dismembered laparoscopic pyeloplasty was recommended in children without a crossing vessel.

Similar to the above-mentioned studies, we performed a retroperitoneoscopic pyeloplasty in 41 children with UPJO and a median age of 130 months (5-192) performing both techniques (dismembered and non-dismembered retroperitoneoscopic pyeloplasty). We present our experience and findings comparing dismembered (Anderson-Hynes) and nondismembered (Y-V-plasty) retroperitoneoscopic pyeloplasty.

\section{Materials and methods}

Between 1997 and 2010, dismembered and non-dismembered retroperitoneoscopic pyeloplasty was performed in
41 children ( 26 males and 15 females) with a median age of 130 months (range 5-192). Indications for surgery were symptoms (flank pain and associated urinary tract infections) and deterioration in renal function based on the furosemide nephrogram findings. 20 children underwent a dismembered pyeloplasty (Anderson-Hynes) and 21 children had a non-dismembered pyeloplasty (Y-V-Plasty); 16 had surgery to their right kidney, while the remaining children had surgery on the left side.

We strongly believe that the preoperative insertion of a ureteric stent can easily be performed during the same anaesthesia and provides a clear benefit particularly in patients with difficult intraoperative conditions. These include children who may have had a number of pyelonephritic episodes that could make the overview in the retroperitoneal space more difficult. The preoperatively inserted ureteric stent thus provides a more visible landmark during the surgery and can easily be removed after

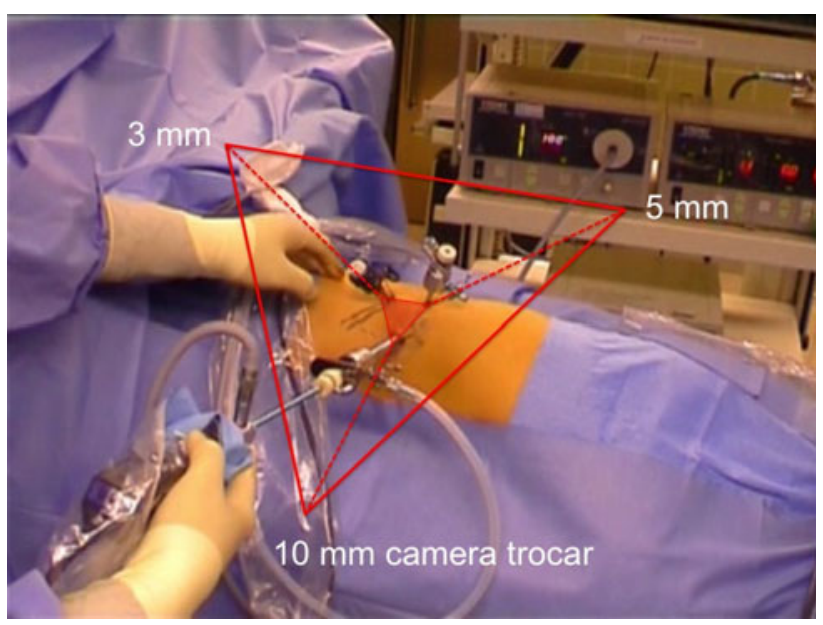

Fig. 1 Trocar position for the retroperitoneal approach (right side)

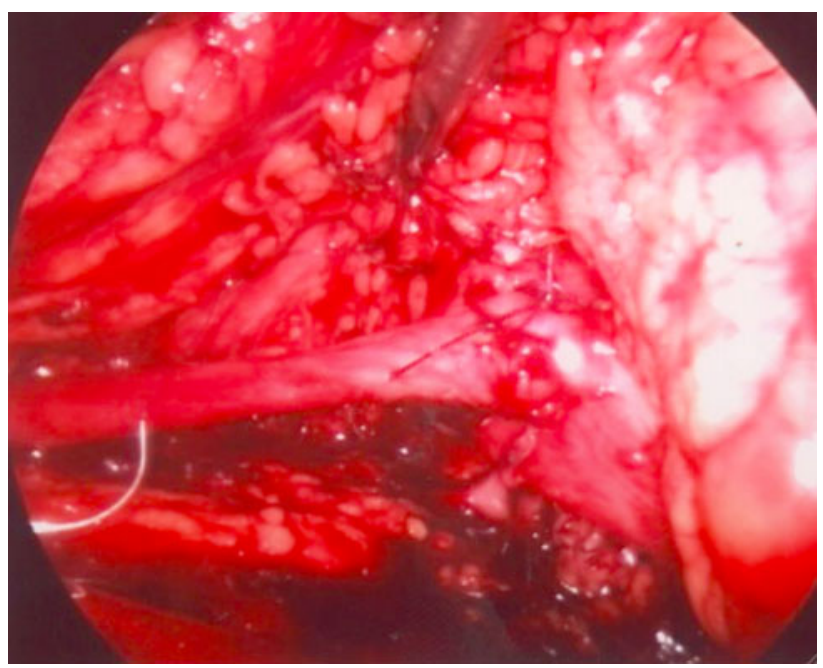

Fig. 2 Non-dismembered Y-V pyeloplasty 
the postoperative ureteropyelography. We prefer to avoid any percutaneous drainage in this procedure to reduce any further risk of traumatization particularly when operating in children.

According to the published survey, success is defined as follows [19]:

(1) Excellent success is a complete absence of symptoms, significant improvement of hydronephrosis and renal drainage on either IVP or diuretic renal scan.

(2) Improvement of symptoms and no deterioration of hydronephrosis (i.e. stable ectasia of the collecting system) or renal function.

(3) Failure: no improvement of hydronephrosis and renal function.

Following surgery at our centre, success was verified on the basis of improved subjective symptoms such as flank pain as well as by a furosemide nephrogram after a period of 3 and 12 months postoperatively. Subjective complaints were evaluated by a questionnaire (pain, recurrence in urinary tract infections with or without requiring additional intervention). Success was defined as symptomatic resolution (i.e. more than $80 \%$ pain relief) associated with either stable or improved renal function, improved washout from the renal pelvis (i.e. T1/2 less than $20 \mathrm{~min}$ ) seen on either a renal scan or excretory urography, and by a resistance index of less than 0.75 .

\section{Surgical technique}

Patients are placed laterally in the flank position. The access to the retroperitoneum is gained via an incision and a muscle-splitting blunt dissection in the region of the muscle-free triangle between $\mathrm{M}$. obliquus externus, $\mathrm{M}$. latissimus dorsi and the iliac crest (Petit triangle). This can be well exposed even in children. We use a $10-\mathrm{mm}$, a $5-\mathrm{mm}$ and a 3-mm trocar that are arranged in a triangular format (Fig. 1), whereby the right $(5 \mathrm{~mm})$ and left $(3 \mathrm{~mm})$ trocars form the ventral basis, while the optic $(10 \mathrm{~mm})$ trocar is the dorsal point of this triangle. Alternatively, a 5-mm optic can be used, where the 10-mm trocar can allow for the transfer of the needle and the delivery and use of 10 -mm clips in special cases.

The entire lumbar ureter is isolated from the surrounding structures such as the aberrant vessels (i.e. lower pole artery), periureteric bands or scar tissue. Additionally, the renal pelvis is dissected; freed and aberrant vessels are completely isolated. The pelvis is incised just superior to the UPJ followed by a vertical incision of the ureter over the indwelling stent in order to evaluate the severity and length of the stenosis. In case of an anteriorly crossing vessel and a short-segmented UPJ-stenosis, the ureter can

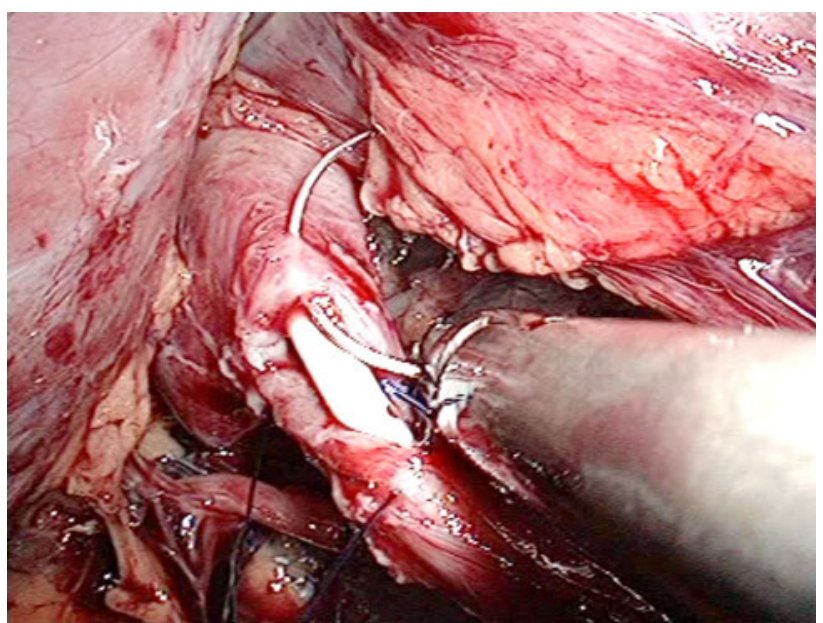

Fig. 3 Dismembered pyeloplasty (Anderson-Hynes)

be further spatulated followed by a horizontal incision of the pelvis (Y-incision). Thereafter, a non-dismembered pyeloplasty $(\mathrm{YV})$ is performed using a continuous suture (4/0, PDS, 15 cm, RB1-needle; Ethicon, Hamburg, Germany) (Fig. 2). In other cases where a dismembered pyeloplasty is indicated, reduction of the renal pelvis is performed using a continuous suture with either two filaments or applying the single-knot technique as described by van Velthoven (Fig. 3). The inserted drain is removed on day 3, and if no extravasation occurs, the Foley catheter may also be removed on the same day.

We performed a Y-V-plasty in cases with anterior crossing vessels, while those with a posterior crossing vessel and/or a redundant pelvis were treated with a dismembered Anderson-Hynes pyeloplasty.

\section{Results}

All 41 operated children continued to be followed-up with a median time of 69 months (14-142). Mean operating time was $120 \mathrm{~min}$ (range 52-257). The intraoperative course was uneventful in all children. The postoperative complication rate was low with only 2 reported urinary tract infections and 1 patient with an urinoma treated conservatively. Intraoperative findings revealed in 31 (76\%) cases an extrinsic cause for the UPJO, including 29 children $(93.5 \%)$ with significant crossing vessels. Focussing on these 29 children, in 25 (86 \%) of them, aberrant vessels alone were identified. 16 (64\%) were found ventrally, 5 $(20 \%)$ dorsally, while the other cases had either circumflex $(n=3,12 \%)$ or a combination of dorsal and ventral vessels $(n=1,4 \%)$ (Fig. 4). The results are summarized in Table 1. Based on a furosemide nephrogram and subjective complaints, the overall success rate was $88 \%$. These results are summarized in Tables 1 and 2. 


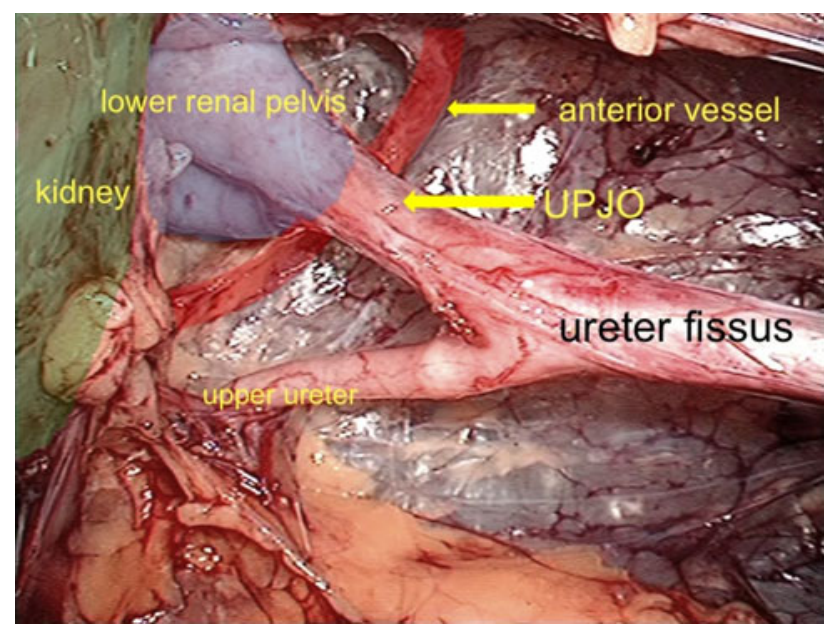

Fig. 4 Anterior crossing vessel in retroperitoneoscopic pyeloplastyhigh ureter fissus (right side)

Table 1 Results for the children subjected to the reason of UPJO (Follow-up $n=41$ )

\begin{tabular}{lclcl}
\hline Reason & $N$ & $(\%)$ & \multicolumn{2}{c}{ Success $(\%)$} \\
\hline Overall & 41 & & 34 & 88 \\
Intrinsic & 10 & 24 & 9 & 90 \\
Extrinsic & 31 & 76 & 27 & 87.1 \\
Vessels & 29 & 93.5 & 25 & 86.2 \\
$\quad$ Vessels alone & 25 & 86 & 22 & 88 \\
$\quad$ Ventral & 16 & 64 & 14 & 87.5 \\
$\quad$ Dorsal & 5 & 20 & 4 & 80 \\
$\quad$ Circumflex & 3 & 12 & 3 & 100 \\
$\quad$ Dorsal + ventral & 1 & 4 & 1 & 100 \\
$\quad$ Vessels (ventral) + adhesions & 4 & 14 & 3 & 75 \\
Adhesions & 2 & 6.5 & 2 & 100 \\
\hline
\end{tabular}

Table 2 Results of different operation techniques for the present series (Follow-up $n=41$ )

\begin{tabular}{lll}
\hline Technique & $N$ & $\begin{array}{l}\text { Success } \\
\text { rate }(\%)\end{array}$ \\
\hline Anderson-Hynes plasty & 20 & 85 \\
Y-V-plasty & 21 & 90.5 \\
\hline
\end{tabular}

The 5 failures (2 Y-V-plasty, 3 AHP) occurred in the early postoperative phase, 3 month after operation (Table 3). One child after AHP suffered from severe pyelonephritis with need for DJ-Stent insertion. Significant obstruction confirmed on the furosemide nephrogram was detected in the other 4 children. Two of these children suffered persisting flank pain and increasing dilation of the collecting system. Finally, one child was treated by a second retroperitoneoscopic AHP, two children received an
Table 3 Data for children with postoperative failure $(n=5)$

\begin{tabular}{llcllll}
\hline $\begin{array}{l}\text { Patient } \\
\text { Nr. }\end{array}$ & $\begin{array}{l}\text { Age } \\
\text { (month) }\end{array}$ & Sex & Treatment & $\begin{array}{l}\text { Reason } \\
\text { for } \\
\text { UPJO }\end{array}$ & $\begin{array}{l}\text { Vessel } \\
\text { position }\end{array}$ & $\begin{array}{l}\text { Revision } \\
\text { operation }\end{array}$ \\
\hline 1 & 5 & M & AHP & Intrinsic & - & $\begin{array}{c}\text { Open } \\
\text { AHP }\end{array}$ \\
2 & 46 & M & YVP & Vessel & Ventral & $\begin{array}{c}\text { Open } \\
\text { AHP }\end{array}$ \\
3 & 71 & M & AHP & Vessel & Ventral & LEP \\
4 & 192 & F & AHP & Vessel & Dorsal & LEP \\
5 & 192 & M & YVP & Vessel & Ventral & R-AHP \\
\hline
\end{tabular}

AHP Anderson-Hynes Plasty, YVP YV-Plasty, LEP laser endopyelotomy, $R$-AHP retroperitoneoscopic Anderson-Hynes Plasty

open AHP and two children underwent a Laser endopyelotomy. All 5 failures are pain free and do not show an obstruction in the furosemide nephrogram after revision intervention at this point of follow-up.

\section{Discussion}

Ureter peristalsis is particularly formed in the proximal regions of the kidney collecting system and transmitted by conduction [20]. In the pyeloureteral junction region, it comes, however, to a physiological blockade, which is modulated according to the diuretic portion.

The first definition of the UPJO on the basis of hydrodynamic criteria was reported in 1977 by Johnston [20]. Two different causes were described: In primary UPJO (intrinsic), irregularities or even complete blockades of the conduction system were found and in other cases, extrinsic causes were recognized.

Johnston et al. found intrinsic or dysfunctional segments that resulted in a clockwise rotation of the collecting system and thus a migration of UPJ in a higher and more medial position. Musculature and elastic fibres of the collecting system try to compensate the increased resistance of outlet. Intrinsic UPJO is particularly found in children and infants. According to the hypothesis of adynamic segments, a dismembered pyeloplasty was established by AndersonHynes for this kind of UPJO.

In the literature, crossing vessels have been identified as the main reason for extrinsic cause of the UPJO [21]. These extrinsic mechanical factors lead to a narrowing of the UPJ and thus result in hydronephrosis. However, whether crossing vessels are the cause for UPJO or only a coincidental finding is still under debate. It has been discussed that asymptomatic patients with crossing vessels have an increased risk for developing UPJO in further life [22].

Surgery is established in the treatment for UPJO. However, some authors still prefer a conservative approach 
in UPJO. Palmer et al. [23] published a study comparing conservative treatment versus surgery. This multi-centre, prospective and randomized phase III study showed a significant reduction in the degree of hydronephrosis in the group treated with surgery, and almost similar findings were found in the conservative group. However, 4 of 16 cases in the conservative group showed a clear reduction in renal function with increased hydronephrosis (that met the criteria for a pyeloplasty).

The indication for surgery is based on guidelines from the SFU that is summarized by the findings of significant deterioration in renal function and hydronephrosis. Symptoms related to recurring urinary tract infections and flank pain are considered likewise as indications for surgery [1]. On the contrary, an ultrasound finding of a persisting hydronephrosis plays no significant role in the decision to operate especially since this finding may be stable and there may in fact not be any evidence of obstruction. Even, previously operated patients may show a 'baggy' system if their pyeloplasty had not entailed sufficient trimming of the collecting system.

In experienced hands, RI, however, may offer a minimally invasive method in specific cases to confirm a suspicious diagnosis such as recurrence of obstruction. The RI should still be regarded as a supplementing method for the determination of pressure ratios and has almost totally replaced the Whitaker test in paediatric urology. Determination of the RI with its advantage of minimal invasiveness spares children and infants the need for furosemide nephrogram assessments. The reliability of this method is described in the literature [21, 24]. Classification of the hydronephrosis degree, relationship between the collecting system and renal parenchyma, and the detection of possible aberrant vessels as well as determination of the RI are the theoretical advantages of duplex ultrasound. A cut-off value of 0.75 is accepted as the value for an obstruction within an insufficiently draining collecting system. We recommend a postoperative ultrasound or coloured duplex ultrasonography including determination of RI every 3 months in the first year and 6 monthly in second year.

Regarding the recently published literature for laparoscopic pyeloplasty, success rates are reported up to $100 \%$ with low complication rates $[4,7,18,25,26]$. We, however, stress the fact that the laparoscopic technique still represents a technically challenging procedure even in adult patients. The laparoscopic technique should only be performed in laparoscopic units with a high patient turnover and established experience in laparoscopic suturing techniques. After the first description by Kavoussi [14] and Schuessler [17], Tan reported in 1996 for the first time of 6 children, who were treated with a laparoscopic pyeloplasty [27]. Although 5 children had successful outcomes as reported and though the author had concluded with a short follow-up that laparoscopic pyeloplasty remains technically difficult and is a promising alternative to conventional open pyeloplasty, long-term results are lacking. Due to the limited retroperitoneal space in children, the transperitoneal approach has been more frequently selected by many surgeons (Table 4). Success rates have been demonstrated ranging from 87 to $100 \%$. There is still no data showing any superiority of transperitoneal or retroperitoneal approach. However, there is a theoretically increased risk of causing abdominal organ injuries with the transperitoneal approach. Finally, the preference and experience of the surgeon should determine the choice of the access used. In our hospital, the retroperitoneal approach was established 10 years prior to us, undertaking this approach in laparoscopic pyeloplasty. This approach has proven its reliability in numerous of kidney surgical interventions including nephrectomy, partial nephrectomy and pyeloplasty. However, when dealing with horseshoe kidneys, the transperitoneal approach should be considered [5].

In earlier series, high conversion rates and long operating times were seen for both techniques, transperitoneal and retroperitoneal approach. Surgeons with vast laparoscopic experience have reported average operating times of 90 min (70-160) [29]. Recently published data as well as our data are summarized in the Table 4. Comparable results to the open technique concerning the operative and postoperative measure points have also been shown [3].

With increasing experience in laparoscopic suturing techniques, the dismembered pyeloplasty represents in experienced hands an alternative method to the open pyeloplasty (Anderson-Hynes). An important factor for success is the degree of hydronephrosis. According to our experience with the adult laparoscopic pyeloplasty, an enlarged distended pelvis does not guarantee sufficient draining and should be treated by dismembered pyeloplasty including trimming of the collecting system. In the case of aberrant vessels, a transposition of the ureter should also be performed [19]. If aganglionic (dysfunctional) segments are suspected in the development of a UPJO, a Y-V plasty is justified and this corresponds to a three-fourth AndersonHynes plasty including spatulation of the ureter. To our knowledge, there is only one study that compared dismembered and non-dismembered laparoscopic pyeloplasty for the treatment of UPJO in children, reporting significant advantage for the dismembered technique (94\% dismembered vs. $43 \%$ non-dismembered)[7]. However, non-dismembered pyeloplasty was not performed in children in case of a crossing vessel and therefore not considered for this evaluation. In the present series, we found 29 children with a significant crossing vessel. The success rate for this children included in the follow-up with crossing vessels was $86.2 \%$ and thus only slight worse to the overall success rate of $88 \%$ (Table 1). Comparing the two different 
Table 4 Recently published studies and results for the present series

\begin{tabular}{|c|c|c|c|c|c|c|c|c|}
\hline Authors & $\begin{array}{l}\text { Patients } \\
(n)\end{array}$ & Age (month) & $\begin{array}{l}\text { Approach } \\
\text { (T/R) }\end{array}$ & $\begin{array}{l}\text { Technique } \\
\text { (D/ND) }\end{array}$ & $\begin{array}{l}\text { Operation time } \\
(\mathrm{min})\end{array}$ & $\begin{array}{l}\text { Success } \\
\text { rate } \\
(\%)\end{array}$ & $\begin{array}{l}\text { Complications } \\
\text { (n) }\end{array}$ & $\begin{array}{l}\text { Conversions } \\
(n)\end{array}$ \\
\hline Subotic et al. [28] & 39 & $\begin{array}{l}\text { Lap: } 11(1-33) \\
\text { Robo: } 115 \\
\quad(58-179)\end{array}$ & $\mathrm{T}$ & $\begin{array}{l}\text { D (20 Lap/19 } \\
\text { Robo) }\end{array}$ & $\begin{array}{l}\text { Lap: } 248 \\
\quad(165-334) \\
\text { Robo: } 165 \\
(104-225)\end{array}$ & 100 & 0 & 0 \\
\hline Canon et al. [6] & 49 & $\begin{array}{l}\text { T: } 78(8-180) \\
\text { R: } 103.2 \\
\quad(24-228)\end{array}$ & $\begin{array}{l}\mathrm{T}(20) / \\
\mathrm{R}(29)\end{array}$ & $\mathrm{D}$ & $\mathrm{T}: 185 / \mathrm{R}: 239$ & $100 / 93$ & 6 & 1 \\
\hline Kutikov et al. [18] & 8 & $4.5(3-5)$ & $\mathrm{T}$ & $\mathrm{D}$ & 108 & 100 & 0 & n.m. \\
\hline $\begin{array}{l}\text { Metzelder et al. } \\
\text { [25] }\end{array}$ & 46 & $66(2-205)$ & $\mathrm{T}$ & $\mathrm{D}$ & $175(120-270)$ & 96 & 1 & 2 \\
\hline Atug et al. [4] & 7 & $144(72-180)$ & $\mathrm{T}$ & D (Robot) & $184(165-204)$ & 100 & 0 & 0 \\
\hline Reddy et al. [26] & 16 & $5-132$ & $\mathrm{~T}$ & $\mathrm{D}$ & $169(90-270)$ & 100 & 0 & 0 \\
\hline Casale et al. [7] & 26 & $60(8-172)$ & $\mathrm{T}$ & D (19), ND (7) & $186 / 150$ & $94 / 43$ & 0 & 0 \\
\hline Tan [29] & 18 & $17(3-180)$ & $\mathrm{T}$ & $\mathrm{D}$ & $90(70-160)$ & 87 & 2 & 0 \\
\hline Bonnard et al. [5] & 22 & $88(25-192)$ & $\mathrm{R}$ & $\mathrm{D}$ & $219(140-310)$ & 96 & 3 & 2 \\
\hline Farhat et al. [30] & 11 & $99(54-143)$ & $\mathrm{R}$ & $\mathrm{D}$ & $160(121-193)$ & 100 & 1 & 2 \\
\hline $\begin{array}{l}\text { El-Ghoneimi et al. } \\
{[12]}\end{array}$ & 22 & $96(20-204)$ & $\mathrm{R}$ & $\mathrm{D}$ & $228(170-300)$ & 100 & 1 & 4 \\
\hline Present series & 41 & $123(5-192)$ & $\mathrm{R}$ & $\mathrm{D}(20), \mathrm{ND}(21)$ & $120(52-257)$ & $85 / 91$ & 5 & 0 \\
\hline
\end{tabular}

$T$ transperitoneal, $R$ retroperitoneal, $D$ dismembered pyeloplasty and $N D$ non-dismembered pyeloplasty

techniques, we found in our series no statistically significant difference between dismembered and non-dismembered pyeloplasty (Table 2). However, two of the five failures were a dismembered pyeloplasty in case of a crossing vessel (ventral $n=1$, dorsal $n=1$ ). The small patient groups (20 dismembered vs. 21 non-dismembered) have to be taken into consideration, and a larger patient load will maybe increase the evidence of advantages for either technique.

According to the literature, a laparoscopic and/or retroperitoneoscopic approach for children and infants is reproducible, feasible and does not influence the success rate [18]. The choice of the technique, dismembered, respectively, non-dismembered retroperitoneoscopic pyeloplasty, has no impact for the outcome. Even in challenging cases like duplicated collecting systems and UPJO, retroperitoneoscopic approach is safe and feasible. However, it remains questionable whether the good results seen in specialized units can be reproduced in other centres.

\section{Conclusion}

Endourology, laparoscopy and retroperitoneoscopy have completely revolutionized the management of upper tract stenosis. Laparosopic pyeloplasty has in particular achieved similar results compared to the gold standard of open surgery in all aspects, with, however, the benefit of minimal invasiveness. The open dismembered pyeloplasty still remains the gold standard of the UPJO in children. With gradual improvement in suturing techniques, the laparoscopic pyeloplasty represents an alternative method with comparable success rates to the open technique. Our data confirm this. Retroperitoneoscopic pyeloplasty (dismembered and non-dismembered) is safe and effective even in infants.

Conflict of interest The authors do not have any conflict of interest.

\section{References}

1. Fernbach SK, Maizels M, Conway JJ (1993) Ultrasound grading of hydronephrosis: introduction in the system used by the Society for Fetal Urology. Ped Rad 23:478

2. Fung LCT, Steckler RF, Khoury AE, McLoire GA, Chait PG, Churchill BM (1994) Intrarenal resistive index correlates with renal pelvis pressure. J Urol 152:607-611

3. Penn HA, Gatti JM, Hoestje SM, DeMarco RT, Snyder CL, Murphy JP (2010) Laparoscopic versus open pyeloplasty in children: preliminary report of a prospective randomized trial. J Urol 184:690-695

4. Atug F, Woods M, Burgess SV, Castle EP, Thomas R (2005) Robotic assisted laparoscopic pyeloplasty in children. J Urol 174(4 pt 1):1440-1442

5. Bonnard A, Fouquet V, Carricaburu E, Aigrain Y, El-Ghoneimi A (2005) Retroperitoneal laparoscopic versus open pyeloplasty in children. J Urol 173(5):1710-1713 
6. Canon SJ, Jayanthi VR, Lowe GJ (2007) Which is better-retroperitoneoscopic or laparoscopic dismembered pyeloplasty in children? J Urol 178(4 pt 2):1791-1795

7. Casale P, Grady RW, Joyner BD, Zeltser IS, Figueroa TE, Mitchell ME (2004) Comparison of dismembered and nondismembered laparocopic pyeloplasty in the pediatric patient. J Endourol 18(9):875-878

8. Chacko JK, Piaggio LA, Neheman A, Gonzalez R (2009) Pediatric laparoscopic pyeloplasty: lessons learned from the first 52 cases. J Endourol 23(8):1307-1311

9. Chertin B, Rolle U, Farkas A, Puri P (2002) Does delaying pyeloplasty affect renal function in children with a prenatal diagnosis of pelvi-ureteric junction obstruction? BJU Int 90(1):72-75

10. El-Ghoneimi A, Farhat W, Bolduc S, Bagli D, McLorie G, Aigrain Y, Khoury A (2003) Laparoscopic dismembered pyeloplasty by a retroperitoneal approach in children. BJU Int 92(1):104-108

11. El-Ghoneimi A (2004) Laparoscopic management of hydronephrosis in children. World J Urol 22(6):415-417

12. El-Ghoneimi A (2003) Paediatric laparoscopic surgery. Curr Opin Urol 13(4):329-335

13. Inagaki T, Rha KH, Ong AM, Kavoussi LR, Jarrett TW (2005) Laparoscopic pyeloplasty: current status. BJU Int 95(Suppl 2): 102-105

14. Kavoussi LR, Peters CA (1993) Laparoscopic pyeloplasty. J Urol 150:1891-1894

15. Peters CA (2004) Laparoscopy in pediatric urology. Curr Opin Urol 14(2):67-73

16. Tan HL (2001) Laparoscopic Anderson-Hynes dismembered pyeloplasty in children using needlescopic instrumentation. Urol Clin North Am 28(1):43-51

17. Schuessler WW, Grune MT, Tecuanhuey LV, Preminger GM (1993) Laparoscopic dismembered pyeloplasty. J Urol 150:17951797

18. Kutikov A, Resnick M, Casale P (2006) Laparoscopic pyeloplasty in the infant younger than 6 months - Is it technically possible? J Urol 175(4):1477-1479
19. Rassweiler JJ, Subotic S, Feist-Schwenk M, Sugiono M, Schulze M, Teber D, Frede T (2007) Minimally invasive treatment of ureteropelvic junction obstruction: long-term experience with an algorithm for laser endopyelotomy and laparoscopic retroperitoneal pyeloplasty. J Urol 177(3):1000-1005

20. Johnston JH, Evans JP, Glassberg KI, Shapiro SR (1977) Pelvic hydronephrosis in children: a review of 219 personal cases. J Urol 117(1):97-101

21. Frauscher F, Janetschek G, Klauser A, Peschel R, Halpern EJ, Pallwein L, Bartsch G (2002) Laparoscopic pyeloplasty for UPJ obstruction with crossing vessels: contrast-enhanced colour Doppler findings and long-term outcome. Urology 59:500

22. Stern JM, Park S, Anderson JK, Landman J, Pearle M, Cadeddu JA (2007) Functional assessment of crossing vessels as etiology of ureteropelvic junction obstruction. Urology 69(6):1022-1024

23. Palmer LS, Maizels M, Cartwright PC, Fernbach S, Conway JJ (1998) Surgery versus observation for managing obstructive grade 3 to 4 unilateral hydronephrosis: a report from the Society for Fetal Urology. J Urol 159:222-228

24. Shokeir AA, Provoost AP, Nijman RJM (1997) Resistive index in obstructive uropathy. Br J Urol 80:195-200

25. Metzelder ML, Schier F, Petersen C, Truss M, Ure BM (2006) Laparoscopic transabdominal pyeloplasty in children is feasible irrespective of age. J Urol 175(5):688-691

26. Reddy M, Nerli RB, Bashetty R, Ravish IR (2005) Laparoscopic dismembered pyeloplasty in children. J Urol 174(2):700-702

27. Tan HL, Roberts JP (1996) Laparoscopic dismembered pyeloplasty in children: preliminary results. Br J Urol 77(6):909-913

28. Subotic U, Rohard I, Weber DM, Gobet R, Moehrlen U, Gonzalez R (2011) A minimal invasive surgical approach for children of all ages with ureteropelvic junction obstruction.J Pediatr Urol. [Epub ahead of print]

29. Tan HL (1999) Laparoscopic Anderson-Hynes dismembered pyeloplasty in children. J Urol 162(3 Pt 2):1045-1047

30. Farhat W, Afshar K, Papanikolaou F, Austin R, Khoury A, Bagli D (2004) Retroperitoneal-assisted laparoscopic pyeloplasty in children: initial experience. J Endourol 18(9):879-882 